\title{
JUN Family Protein
}

National Cancer Institute

\section{Source}

National Cancer Institute. JUN Family Protein. NCI Thesaurus. Code C18534.

Encoded by JUN Family Genes, nuclear leucine zipper JUN Family Proteins (JUN, JUNB, and JUND) can homodimerize, or heterodimerize with nuclear leucine zipper FOS Family Proteins, to form the specific promoter/enhancer DNA-binding AP-1 transcription factor complex that regulates target gene transcription in cell proliferation, differentiation, and transformation. $(\mathrm{NCl})$ 